and Czermak, Störk, and others, have observed and recorded several examples. The growth is not of the same nature as the usual polypus of the nose, but is, 1 believe, of still lower vitality; unfortunately, the portions removed, which I wanted for microscopic examination, were accidentally thrown away.

Oct. 20 th. - Since the above was written I have seen but little of my patient, as he has been working extra time-that is, from six in the morning until half-past eight in the evening; he is still, however, very hoarse, and wheezes after any great exertion.

In the Association Journal for Oct. 19th, 18i1, a case of "Tumour of the Larynx" is published by Mr. Crosse, of Nor. wich. To those who have any doubt of the practical utility of the laryngoscope $I$ would strongly recommend a perusal of this case, and a comparison of it with that which I have reported above. There can be but little doubt that had such an able surgeon as Mr. Crosse been possessed of the same means of diagnosis which I employed, the result of the case he reports would have been very different, and its treatment would have more resem. bled that which I adopted with such great success.

Peterborough, Oct. 1861.

\section{ON A CASE OF ANEURISM OF THE HEART.} WITH REMARKS UPON ITS EFFICIENT CAUSE.

BY W. STRANGE, M.D., PHYSICIAN TO THE WORCESTRE INFIRMARY.

CAsEs of true aneurism of the heart are correctly enough described in most of our modern works on general pathology, and occasionally fall under our notice when seeking in the dead body for some other form of cardiac disease. They are sufficiently uncommon to make it desirable, nevertheless, that every case of the kind should be briefly recorded, to the end that, from a description of the various other lesions of the heart and great vessels with which it may be accompanit, some conjecture may be formed as to the real force acting in the formation of this kind of aneurism.

$\mathrm{Wm} . \mathrm{C}-$, aged fifty-four, formerly a soldier, invalided from India, lately occupied in gardening, was treated during three months at the Worcester Dispensary for heart disease. The symptoms were chiefly referable to mitral disorder, but without pulmonary congestion. There was a moderate degree of anasarca and scanty urine, which latter, however, was readily increased by diuretics. There was a loud bellows sound over the base and middle part of the heart with the first sound; impulse not strong, sometimes double and confused; the second sound natural. Great pulsation was felt in the epigastrium, and along the course of the abdominal aorta, so much so as to lead one gentleman to believe that there was an aneurism of the aorta. The diagnosis was mitral disease, with hypertrophy and dilatation of the heart, probably aneurism. On examination after death, the heart was found to be everywhere closely attached to the pericardium by old adhesions, and in endeavouring to separate the heart from its bag the fingers lacerated the right ventricle in several places. The heart was largely dilated, especially the right ventricle; substance not thickened, and tissue rather soft and easily lacerable, but of good colour; semilunar valves all healthy; the mitral partly adherent to the base of the left ventricle, but not so as to cause a very patulous state of the auricular orifice. The aneurism was situated nearly in the centre of the left ventricle, having for its base a fibrous rim, which was continuous, by a sort of prolongation, with that portion of the valve which was adherent to the ventricle. The aneurism was lined throughout with strong fibrous tissue, exactly resembling that of the aorta. It would have beld a double walnut, or half a small orange. From a base of about one inch in diameter, it was excavated in the substance of the ventricle, the fleshy structure of which had been gradually removed, so as to leave at the apex of the aneurism nothing but the strong fibrous tissue before described. There was very slight atheromatous deposit in the ascending aorta. The lungs were not congested, and the abdominal viscera were all healthy, except the left kidney, which was highly congested, and a little enlarged. There was some serous effusion into the pleuræ and pericardium.

To which of these lesions can death be attributed in this case? The lungs and abdominal viscera, with the exception of one kidney, being all healthy, and the dropsy but recent and moderate in amount, there was nothing to account for death except the disease of the heart. The aneurism, we will suppose, being merely an appendage to the ventricle, although it might present a considerable impediment to its proper closure during systole, would not so interrupt the motions of the heart as to canse either fatal syncope, or, as was proved, severe pulmonary congestion. I conclude, therefore, that death was brought about by that gradual wearing out of the powers of the heart which all writers on the subject-Hope, Williams, Latham, Watson, and others-attribute to the continuous struggle to pursue its motions whilst fettered by the strong adhesions to the pericardium. These adbesions, when close and firm, as in the present instance, prevent the slightest movement of one serous surface upon the other, and, sooner or later, lead to death as certainly as tubercles in the lungs or fatty deposit in the kidneys. The pericarditis, which left the heart adherent, was doubtless accompanied with endocarditis affecting the mitral valve and the lining membrane of the left ventricle, and at the same time the aneurismal sac was probably formed. The in. flammation which affected the base of the valve would probably extend to some depth into the substance of the ventricle, and the softening resulting from this inflamed condition of the mus. cular substance might admit of the increased impulse dilating the ventricle irregularly so as to form a pouch. This pouch would become the depository of continuous layers of fibrin from the semi-stagnant blood remaining in it after each pulsa. tion. In this way only, I think, can we account for the heart's substance being wanting in the thickest part of the left ventricle, otherwise healthy, and its place being supplied by arterial fibrons tissue. Whether this theory will apply equally well to some other cases of pouches or aneurismal dilatation, which are always seated in, or attached to, the left ventricle, I cannot say.

The lesson taught us, or, rather, reiterated to our minds, by such cases as these, is the danger of half-cured cases of pericarditis. This subject has been so eloquently $\mathrm{d}$ welt upon by Dr. Watson, in his Lectures, as to be capable of no further emphasis from my pen. The lesson is one, however, which all those who find themselves in charge of cases of rheumatic in. flammation of the membranes of the heart ought seriously to consider. Those especially who have caught the modern practice of treating the heart symptoms in these cases in the simple manner which is applicable enough to the general rheumatic symptoms-by alkalies, opium, warm baths, \&c.-should put it to their own minds whether they have done all in their power to lessen or remove the morbid action from the membranes, which, in the generality of the cases, proceeds with slow but sure steps to disorganize the whole structure of the heart. The bruits may cease, the pulse become tranquil, the pain vanish, and the muscular strength return for a time; but those who have charge of public hospitals know well, as Dr. Watson remarks, that years after, the same faces make their reappearance at the hospital, with the unmistakable marks upon them of hopeless disease of heart, lungs, or both. Those who, in the treatment of the disease in its acute stage, scorn mercury, iodine, or the other heroic remedies of our forefathers, are bound to show that the modern do-little practice does not leave, at any rate, a larger proportion of those so treated to return at a future day the miserable objects above described.

P.S. Since the above was prepared for the press, I have read the account in THE LANCET of a discussion on aneurismal dilatation of the heart, at the Medical Society of London. In each of the three cases there mentioned, the dilatation was situated at the apex of the ventricle, and this is its position, so far as I am aware, in most of the cases recorded in works on cardiac pathology. It is easy to believe that general softening, which is greatest in this situation, was the determining cause both of the dilatation and of its position in these cases. The same lesion, however, will not account for the peculiarities of the case recorded above, inasmuch as little or no fatty degeneration had affecied the heart or other viscera. The evidence of former very severe pericardial inflammation tends to the belief that inflammatory, and not fatty, softening was its primary cause.

As illustrative of the effects of true softening of the heart in the production of these pouches, I may mention the following. A few days since I was present at the autopsy of an out.patient of this infirmary who died suddenly in the street. He was between fifty and sixty years of age, pale, puffy, and slightly anasarcous. The apex of the heart presented externally a soft, puffy pouch, having the appearance of the pointing of an

* For a complete analysis of all the cases of this disease recorded at that time, see a paper by Dr. J, Thurnam, in "Med.-Chir. 'Transactions," for 1839" vol, צxi. 
abscess. There were a few old adhesions of the pericardium. On cutting into the ventricle, it was found to be thin, soft, and flabby; the whole of the lower half being converted into a semi-fluid pultaceous mass, in which the muscular fibre floated, completely disintegrated. At the apex itself nothing remained to preveuc rupture but the external serous membrane. The right ventricle was completely filled with a fibrinous clot, dis tinctly divided into two portions, an inner and an outer layer. The inner portion was globular, white, and fatty-looking, and composed of pure fibrin; the outer had some red globules in timately blended with the fibrin, and was much thinner than the inner portion. This unusual state of the clot is to be accounted for, I presume, by the condition of the heart itself; the prolonged stasis of the bloor in the right, owing to the debilitated state of the left ventricle, giving an opportunity for the slow formation of a clot from which the red particles would drain away into the thin current percolating round its sides. The second portion of the clot might have formed during the death-agony, in which, probably, the generality of these deposits are formed. This case therefore presented, I conceive, an instance of the clot which forms during life, greatly embarrassing the circulation, and also of that which doubtless forms during the semi-stasis of the blood immediately preceding the last few pulsatious of the heart.

Worcester, 1861.

\section{9.}

\section{OF THE PRACTICE OF}

\section{MEDICINE AND SURGERY IN THE}

\section{HOSPITALS OF LONDON.}

Nulla est alia pro certo noscendi via, nisi quam plurimas et morborum et dissectionum historias, tam aliorum proprias, collectas habere et inter se comparare,-Morgagni. De Sed. et Caus. Morb., lib. 14. Procmium.

\section{CHARING-CROSS HOSPITAL。}

\section{THIRTY-EIGHT EXOSTOSES GROWING FROM THE EXTREMITIES OF A GIRL.}

\section{(Under the care of Mr. BARWELL.)}

Is reading the notes of the following case, chiefly remarkable for the large number of bony tumours present on the extremities, the question naturally arises, to what source can their presence be attributed? Surgical writers speak of syphilis, scrofula, cancer, and gout as predisposing causes, and they are known oftentimes to be hereditary: sometimes several members of the same family are subject to them. So far as the girl's history goes, no clearly assignable cause can be made out, unless a rheumatic tendency through the father, who has been a martyr to rheumatism almost all his life, be considered as such. He had a bony tumour removed on one occasion from one of his thighs.

As is the usual rule in these cases, the tumours are present on the long bones of the extremities; one only occurs on a flat bonethe scapula. They are not symmetrical, if we except the clavicle, yet they are so far uniform that as many as eighteen occur on the left, and twenty on the right extremity, giving a total of thirty-eight, in a girl who has not attained to puberty. In the young, about the age of puberty is the period most favourable for the appearance of these tumours.

As regards treatment, bony growths are so commonly seen single that very little importance is attached to them; they are removed, and there is no return. This, however, could not be practised in such an example as that under notice. We think there can be no doubt that in their nature they partake of the spongy or cancellous character, being primarily enchondromatous.

F. H - aged fourteen, applied to Mr. Barwell, on the 29 th of July last, for swellings in different parts of her body. Her mother died nine years ayo of consumption; the father has suffered all his life till lately from rhenmatism, and about thirty years ago had a bony tumour removed from one of the thighs by Sir B. Brodie. She is the youngest child ; there have been many born, but all have died except one sister, who is now about twenty, and has a small bronchocele. F. Hhas not menstruated, is of lymphatic temperament, bas al ways had good health, but now suffers from pain in the chest (gastrodynia), and has grown thin lately. She fell down when a few months old and hurt her arm. The surgeon called in seems to have said that she was so fat he could not tell whether a bone was broken; at all events, no fracture was detected. The left forearm is now very much deformed, being bent in. wards a little below its middle at an angle of $35^{\circ}$. The ulna appears to have been broken, and the fragments now override; the radius is bent in a rather abrupt curve over to the ulnar side. At the point of flexion the two bones are very widely separated.

On examining one or two of the swellings which the girl showed, they were found to be exostoses, and so numerous as to render an examination into their actual number and position necessary. A synopsis of them is given below; but their conditions may be stated thus:- The exostoses, thirty-eight in number, vary from the size of a half-pea (and very likely there are smaller ones not detectable) to that of a hen's egg; the smallest being on the fingers, the largest on the thigh. They all occur on bones of the extremities, not one being found on any part of the head or trunk. With one exception, they all have their seat on long bones-the exception is the scapula, and the bony enlargement in that spot is more like a thickening than an exostosis. The bones of the carpus and tarsus are quite free, even though these excrescences are plentifully croping out from long bones in their immediate neighbourhood. Their arrangement is not symmetrical (except at the clavicle). There is a grotesque straiuing after symmetry, as at the thighs (see Table) and in other parts; but it always fails. There is an evident partiality for the ends of the long diaphyses, their centres being less frequently affected, and the epiphyses very rarely.

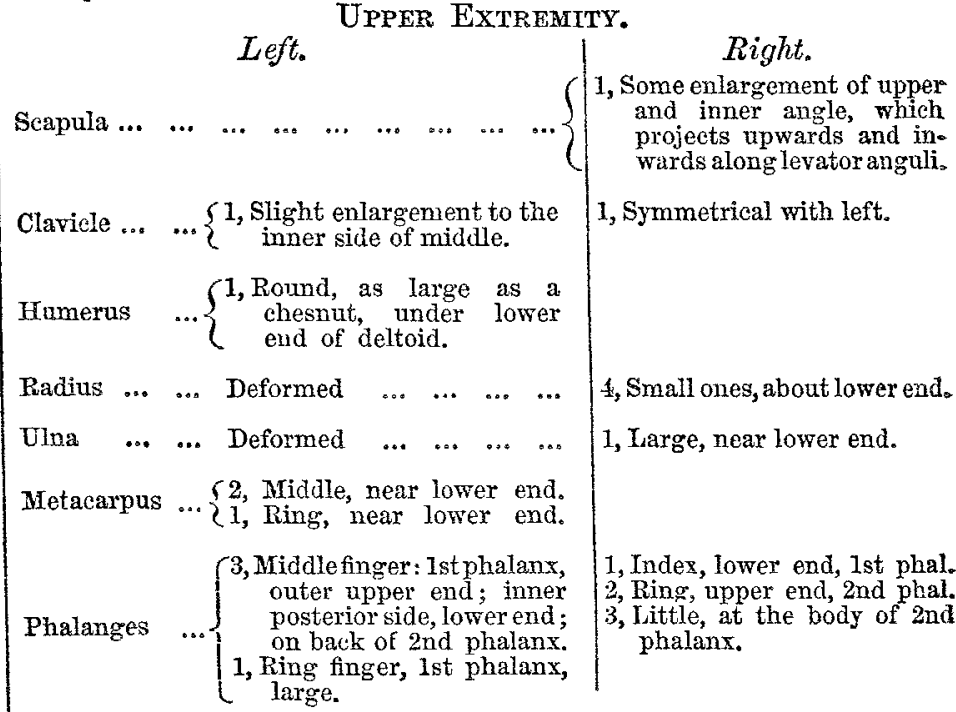

\section{LowER EXTREMITY.}

Fermur $\quad \ldots \quad \ldots\left\{\begin{array}{l}2, \text { Outside, four inches from } \\ \text { lower end, as big as a } \\ \text { hen's egg; inside, abroad, } \\ \text { ragged one, with point } \\ \text { growing out. }\end{array}\right.$
Tibia $\quad \ldots \quad \ldots\left\{\begin{array}{l}5, \text { Three around head, inner } \\ \text { side; two, lower end, } \\ \text { two inches above mal- } \\ \text { leolus, one spur look- } \\ \text { ing forward, the other } \\ \text { backward. }\end{array}\right.$
Fibula $\quad \ldots \quad \ldots\left\{\begin{array}{l}2, \text { Lower end one posterior, } \\ \text { half-inch above malleo- } \\ \text { lus; one outside, on mal- } \\ \text { leolus. }\end{array}\right.$

2, Neither so large as on the left side, and asymmetrical, for inner one is as high as outer of other side, and left inner.

, Upper end: one large craggy one, probably originally composed of three, surrounds the head of the bone. lower end : one projects malleolus.

3, One on head of tone; one at lower end, above malleolus, one at front of malleorsa

Total of tumours on the left side, 18 ; on the right, 20 ; Grand total, 38 .

The large number of these exostoses would decidedly denote some constitutional defect, some unhealthy diathesis, giving rise to such excessive bony growth; but neither the general appearance nor the symptoms present anything to confirm such an idea. Dr. Willshire examined the urine, and found in it nothing abnormal. The condition of the left arm gives somo 